\title{
ACUTE CHLOROQUINE POISONING: A CASE REPORT
}

R. Nigam ${ }^{1}$, S. Chatterjee ${ }^{2}$, M. Murthy ${ }^{3}$, R. Bhure ${ }^{4}$, M. Debbarma ${ }^{5}$

\section{HOW TO CITE THIS ARTICLE:}

R. Nigam, S. Chatterjee, M. Murthy, R. Bhure, M. Debbarma. "Acute Chloroquine Poisoning: A Case Report". Journal of Evolution of Medical and Dental Sciences 2015; Vol. 4, Issue 24, March 23; Page: 4212-4214, DOI: $10.14260 /$ jemds $/ 2015 / 606$

\begin{abstract}
Chloroquine is a widely available drug, used for the treatment of malaria and as prophylaxis for travellers to endemic countries. Despite widespread availability report of chloroquine poisoning as suicidal attempt is rare in India. Here we report a case of a young male who presented to our emergency department with alleged history of ingestion of $3.0 \mathrm{gm}$ of Chloroquine tablets as suicidal attempt. He developed convulsion and cardiac arrest after admission. He was aggressively managed in intensive care unit.
\end{abstract}

KEYWORDS: Chloroquine, poisoning, suicidal.

INTRODUCTION: Chloroquine is a derivative of 4-aminoquinoline, which is used in prophylaxis and treatment of malaria and the therapy of some connective tissue diseases. Owing to its narrow therapeutic index the drug is relatively toxic, especially in the case of an overdose or an acute intoxication.

CASE HISTORY: A 21-year-old male was admitted to our emergency department (ED) with an alleged history of ingestion of 10 tablets of Chloroquine DS (each containing 300mg of chloroquine base) 4 hours prior to admission in a suicidal attempt. His physical examination revealed that he had altered mental status, with the Glasgow Coma Scale of 6 . His heart rate was $50 \mathrm{bpm}$, arterial blood pressure was $70 / 40 \mathrm{~mm} \mathrm{Hg}$. He had respiratory distress and his pulse oxygen saturation was $80 \%$ with face oxygen mask. He was immediately intubated for airway protection but soon after that his clinical condition rapidly deteriorated and he developed cardiac arrest. Epinephrine (1mg) and atropine $(1.2 \mathrm{mg}$ ) were administered intravenously. Cardiopulmonary resuscitation was started and his heart rhythm showed ventricular tachycardia with weak pulse. He received three electrical cardioversion shock. Which established a regular rhythm with a rate of $60 / \mathrm{min}$ and blood pressure of $70 / 50 \mathrm{mmHg}$. He received intravenous normal saline bolus $(20 \mathrm{~mL} / \mathrm{kg})$ and supportive therapy with dopamine infusion $(10 \mathrm{mcg} / \mathrm{kg} / \mathrm{min})$ was started which restored his heart rate to $70 / \mathrm{min}$ and blood pressure to $90 / 50 \mathrm{mmHg}$. He developed generalised tonic clonic seizures immediately after cardiopulmonary resuscitation. His seizure were treated with intravenous diazepam.

A continuous diazepam infusion $(2 \mathrm{mg} / \mathrm{kg} / 24 \mathrm{~h}$ ) was started following the recommendations of previous studies. ${ }^{(1,2)}$ Gastric lavage was performed, and he received activated charcoal when he was haemodynamically stable. His ECG was initially abnormal and the QRS complex was 0.14 sec. wide and returned to normal after 48 hours Laboratory examination revealed a serum potassium level of $2.6 \mathrm{mEq} / \mathrm{l}$, serum bilurubin, AST and ALT, blood urea and serum creatinine were within normal range. Potassium supplementation was started immediately under strict cardiovascular monitoring. He remained haemo dynamically unstable until his clinical condition started to improve by the end of the second day. On the third day, the infusions of dopamine and diazepam were gradually stopped. 


\section{CASE REPORT}

The patient was extubated 72 hours after admission. He subsequently made a complete recovery with no residual neurological deficit and was discharged from the hospital on seventh day.

DISCUSSION: Chloroquine is an antimalarial drug of 4-aminoquinolines group. Chloroquine is the drug of choice for clinical cure and suppressive prophylaxis of all types of malaria, except that caused by resistant P-falciparum. Chloroquine exerts its toxicity by quinidine-like mechanisms: It is a profound negative inotrope and a vasodilator. It slows intraventricular conduction. Oral chloroquine is rapidly and almost completely absorbed, resulting in transiently high blood concentrations early in the distribution phase that are potentially cardiotoxic. ${ }^{(3,4)}$ Patients may also develop severe hypokalaemia, which is strongly related to the severity of toxicity. Chloroquine toxicity may also present with drowsiness, irritability, vertigo, visual disturbances, convulsions, QRS widening, abdominal cramps, vomiting and apnoea.(5)

Ingestion of $5 \mathrm{gm}$ of chloroquine is found to be almost fatal within four hours without treatment and life threatening cardiac arrhythmia has been reported even with $150 \mathrm{mg}$ of Chloroquine as a single dose.(6) Riou et al. have identified systolic blood pressure $<90 \mathrm{mmHg}$, QRS complex duration $>0.12 \mathrm{sec}$., dose $>5 \mathrm{gm}$ and blood chloroquine concentration $>25 \mathrm{mcg} \mathrm{mol} / \mathrm{l}$ as predictors of a fatal outcome in chloroquine poisoning and recommended the use of diazepam infusions to treat severe cases in whom a fatal outcome would previously have been expected.(5) Diazepam is a valuable therapeutic agent in experimental chloroquine poisoning, it counteracts some hemodynamic and electrocardiographic changes, and increased urinary excretion of chloroquine in experimental chloroquine poisoning, but diazepam cannot be considered as an antidote against chloroquine.(1,2)

The management of severe chloroquine intoxication involves control of airway, breathing and circulation, prevention of further absorption, stabilizing the cardiovascular system and aggressively managing hypokalemia. Activated charcoal absorbs chloroquine very effectively from the gastrointestinal tract (GIT), and should be administered as soon as possible in known or suspected chloroquine poisoning.(7) Haemoperfusion is ineffective as chloroquine has a large volume of distribution in the blood and is highly concentrated in the red blood cells. ${ }^{8)}$ In summary, chloroquine should be kept in mind as a possible offending agent in patients who present to the ED with circulatory failure, conduction disturbance, and seizures, especially following a suicide attempt.(9)

\section{REFERENCES:}

1. Riou, B., Barriot, P., Rimailho, A. \& Baud, F. Treatment of severe chloroquine poisoning. N Engl J Med 1988; 318: 1-6.

2. Riou, B., Rimailho, A., Galliot, M., Bourdon, R. \& Heut, Y. Protective cardiovascular effects of diazepam in experimental acute chloroquine poisoning. Intensive Care Med 1988; 14: 610-616.

3. Gustaffson, L., Walker, O., Alvan, G. et al. Disposition of chloroquine in man after single intravenous and oral doses. Br J Clin Pharmacol 1983; 15: 471-479.

4. Don Michael TA, Aiwazzadeh S. The effects of acute chloroquine poisoning with special reference to the heart. Am HeartnJ 1970; 79: 831-42.

5. Lofaso F, Baud FJ, Halna du Fretay X, Bismuth C, Staikowsky F, Sidhom N. Hypokalaemia in massive chloroquine poisoning. 2 cases. Presse Med 1987; 16: 22-4. 


\section{CASE REPORT}

6. Parul S, Singhal A K, Sant K. Cardiac Arrhythmia following single small dose of Chloroquine. Indian J Pharmacol 1989; 21: 163-167.

7. Neuvonen PJ, Kivistö KT, Laine K, Pyykko K. Prevention of chloroquine poisoning by activated charcoal. Hum Exp Toxicol 1992; 11: 117-20.

8. Boereboom, Ververs F, Meulenbelt J, van Dijk A. Hemoperfusion is ineffectual in severe chloroquine poisoning. Crit Care Med 2000; 28: 3346-50.

9. Phipps C, Chan K, Teo F, Ponampalam R. Fatal chloroquine poisoning: a rare cause of sudden cardiac arrest Ann Acad Med Singapore. 2011 Jun; 40 (6): 296-7.
AUTHORS:
1. R. Nigam
2. S. Chatterjee
3. M. Murthy
4. R. Bhure
5. M. Debbarma

\section{PARTICULARS OF CONTRIBUTORS:}

1. Associate Professor, Department of Anaesthesiology, Chhattisgarh Institute of Medical Science, Bilaspur.

2. Professor, Department of Anaesthesiology, Chhattisgarh Institute of Medical Science, Bilaspur.

3. Associate Professor, Department of Anaesthesiology, Chhattisgarh Institute of Medical Science, Bilaspur.

FINANCIAL OR OTHER

COMPETING INTERESTS: None
4. Senior Resident, Department of Anaesthesiology, Chhattisgarh Institute of Medical Science, Bilaspur.

5. Assistant Professor, Department of Anaesthesiology, Chhattisgarh Institute of Medical Science, Bilaspur.

\section{NAME ADDRESS EMAIL ID OF THE CORRESPONDING AUTHOR:}

Dr. Rakesh Nigam, House No. 23, OM Garden, Parijat Colony, Neharu Nagar, Bilaspur (C. G.).

E-mail: bangonigam@gmail.com

Date of Submission: 25/02/2015. Date of Peer Review: 26/02/2015. Date of Acceptance: 10/03/2015. Date of Publishing: 23/03/2015. 